\title{
The Relationship of Action Research to Human-Computer Interaction
}

\author{
GILLIAN R. HAYES, University of California, Irvine
}

\begin{abstract}
Alongside the growing interest within HCI, and arguably computing more generally, in conducting research that has substantial societal benefits, there is a need for new ways to think about and to articulate the challenges of these engaged research projects as well as their results. Action Research (AR) is a class of methods and approaches for conducting democratic and collaborative research with community partners. AR has evolved over the last several decades and offers HCI researchers theoretical lenses, methodological approaches, and pragmatic guidance for conducting socially relevant, collaborative, and engaged research. In this article, I describe the historical context and origins of AR, the scientifically rigorous practice of conducting and evaluating AR projects, and the ways in which AR might meaningfully be applied to HCI research
\end{abstract}

Categories and Subject Descriptors: D.2.10 [Software Engineering]: Design—methodologies; H.5.2 [Information Interfaces and Presentation]: User Interfaces; K.4.2 [Computers and Society]: Social Issues

General Terms: Design, Human Factors

Additional Key Words and Phrases: Action research, collaborative inquiry

ACM Reference Format:

Hayes, G. R. 2011. The relationship of action research to human-computer interaction. ACM Trans. Comput.Hum. Interact. 18, 3, Article 15 (July 2011), 20 pages.

DOI $=10.1145 / 1993060.1993065$ http://doi.acm.org/10.1145/1993060.1993065

\section{INTRODUCTION}

In recent years, the Human-Computer Interaction community has shown significant interest in doing research that has inherent value to society. These efforts to address human issues through computing solutions have benefits beyond their intended contributions to research and to society-there is also evidence that these kinds of projects help bring women and other underrepresented groups into computing [Margolis and Fisher 2003; Hochheiser and Lazar 2007].

The growing interest in socially relevant HCI can be seen most visibly in two ways. First, the CHI Social Impact Award was first given in 2005, and since then significant recognition has been drawn to efforts focused on connecting substantial human issues with innovative computing solutions. Second, a comparison between the proceedings of the 1990, 2000, and $2010 \mathrm{CHI}$ conferences-based on examination of titles, abstracts, and keywords-shows a substantial upward trend in the publication of civically engaged research. The theme of the $1990 \mathrm{CHI}$ conference was "Empowering People" and yielded numerous lab reviews and papers describing new input techniques

This work was supported in part by NSF ITR Grant 0121661, NSF CAREER Grant 0846063, Intel Corporation, Google Research, IBM Research, the Robert Wood Johnson Foundation, and AutismSpeaks.

Authors' address: G. R. Hayes, Department of Informatics, Donald Bren School of Information and Computer Sciences, University of California, Irvine, Irvine, CA 92697, email: gillianrh@ics.uci.edu.

Permission to make digital or hard copies of part or all of this work for personal or classroom use is granted without fee provided that copies are not made or distributed for profit or commercial advantage and that copies show this notice on the first page or initial screen of a display along with the full citation. Copyrights for components of this work owned by others than ACM must be honored. Abstracting with credit is permitted. To copy otherwise, to republish, to post on servers, to redistribute to lists, or to use any component of this work in other works requires prior specific permission and/or a fee. Permissions may be requested from Publications Dept., ACM, Inc., 2 Penn Plaza, Suite 701, New York, NY 10121-0701 USA, fax +1 (212) 869-0481, or permissions@acm.org.

(c) 2011 ACM 1073-0516/2011/07-ART15 $\$ 10.00$

DOI 10.1145/1993060.1993065 http://doi.acm.org/10.1145/1993060.1993065 
and interface designs for doing just that. None of the 47 accepted papers, however, explicitly focused on solving a human problem beyond the interaction between people and their computing systems, primarily in classrooms or workplaces. Of the 72 papers accepted in 2000 with a theme less explicitly about engaging with societal problems ("The Future is Here"), however, two (2.8\%) focused on the implementation of solutions to address societal needs as primary foci [Jancke et al. 2000; Benford et al. 2000] and by 2010 - with an arguably inclusive and collaborative theme "We are HCI"-this number had grown to 50 (16.6\%) of 302 accepted papers. These papers included issues related to healthcare (e.g., [Ramachandran et al. 2010; Wilcox et al. 2010]), education (e.g., [Balaam et al. 2010; Hirano et al. 2010]), sustainability and Green IT (e.g., Kim and Paulos [2010]; Kuznetzov and Paulos [2010]), HCI solutions for developing and conflict-ridden nations (e.g., Smyth et al. [2010]; Gitau et al. [2010]) and so on. Inclusion criteria for these papers required that they not only be about some domain problem of societal and human need but also that they address an implementation of some intervention for these challenges, a connection that will become more clear as I outline the origins and practice of Action Research. However, had I included papers related to these topics (health, education, sustainability, and so on) that are not intervention based, the numbers would be even higher in 2010 .

The rise in research oriented towards improving social well-being has been accompanied by a less extreme increase in participatory, cooperative, and democratic design orientations. Participatory Design (PD) conferences have been held biannually since $1990^{1}$ and have grown from small events focused on opening up conversations between design communities to an international conference complete with research papers, poster sessions, and so on. By examining titles, abstracts, and keywords for CHI 1990, 2000 , and 2010 for papers explicitly focused on participatory and cooperative methods, potential growth in these areas of interest were also seen. A paper and a panel were focused specifically on Cooperative or Participatory Design in 1990 [Johnson 1990; Blomberg and Henderson 1990], two papers in 2000 [Damn et al. 2000; Mäkelä et al. 2000], and four in 2010 [Walsh et al. 2010; Yoo et al. 2010; Bach and Twidale 2010; Tarkan et al. 2010]. Participatory approaches have become so ingrained in research in the CHI community that the counts of papers would be much higher than one, two, and four in these respective years if they were to include any papers that had any elements of participation in them rather than just those that were focused on these methods and approaches.

Despite the substantial growth in interest in collaborative approaches that engage real human problems and have at their heart the idea of creating workable solutions to these problems, some researchers still express concerns about how scientific and systematic these efforts are. Debates continue to rage on the need for "generalizability" of a particular solution [Baskerville and Lee 1999; Lee and Baskerville 2003], for the numeric and methodical accounting of the science in the scholarship, and so on. At the same time, there are enormous questions about how feasible solutions are when developed without intense, and sometimes very messy, engagement with the people and problems that lie at the heart of these projects [Stolterman 2008].

Action Research (AR) offers a systematic collaborative approach to conducting research in HCI that satisfies both the need for scientific rigor and promotion of sustainable social change and has been taken up by a variety of researchers in HCI (e.g., [Foth and Axup 2006; Palen 2010]) and Information Systems (e.g., Baskerville and PriesHeje [1999] research. AR "aims to contribute both to the practical concerns of people" in problematic situations and to the academic goals of science "by joint collaboration with a mutually acceptable ethical framework" [Rapaport 1970, p. 499]. Procedurally,

\footnotetext{
${ }^{1}$ http://www.pdc2010.org/about/pdc-conferences/.
} 
$\mathrm{AR}$ is "comparative research on the conditions and effects of various forms of social action, and research leading to social action" that uses "a spiral of steps, each of which is composed of a circle of planning, action, and fact-finding about the result of the action" [Lewin 1946; 1948]. AR is not necessarily a method but instead "a series of commitments to observe and problematize through practice a series of principles for conducting social enquiry" [McTaggart 1996, p. 248].

AR is explicitly democratic, collaborative, and interdisciplinary. The focus when conducting AR is to create research efforts "with" people experiencing real problems in their everyday lives not "for", "about", or "focused on" them. Thus, AR research focuses on highly contextualized, localized solutions with a greater emphasis on transferability than generalizability.

$\mathrm{AR}$ is not the first approach to view research as democratic and inclusive. Pragmatists—such as John Dewey [Dewey 1976] and William James [James 1948] laid the foundation for a view of science that is complex, humanly meaningful, and available to everyone [Greenwood and Levin 2007, p. 59]. Dewey, in particular, can be credited with significant influence in the change in thought patterns that allowed for the possibility of such participative approaches as AR. Dewey noted that scientific judgment is not a form of "esoteric knowledge". Rather, he believed that all humans are capable of scientific judgment, that many people make these judgments every day without acknowledging them as such, and that all of society would be improved with greater involvement in the scientific process. He further argued that scientific knowing, like all forms of knowing, is a product of continuous cycles of action and reflection [Dewey 1991/1927]. In his view, thoughts must not—indeed perhaps cannot-be separated from action. During his time as a professor at MIT, Kurt Lewin took up the goal of a more holistic and humanistic approach to research laid by these early pragmatists [Lewin 1935] with an approach to work and ideals of research that eventually developed into his concept of action research, a path described in more detail in the next section on the history of AR.

Nearly a century after Dewey and the other original pragmatists began writing about their ideals and following decades of controversial writings on AR, Richard Rorty described a division between systematic philosophy and edifying philosophy. In Rorty's view, systematic philosophy is the search for an absolute reality determined by philosophical experts (e.g., scientists, researchers, theorists). Edifying philosophy, on the other hand as advocated by Rorty, is an ongoing conversation involving methods and debates that attempt to bring people into "communicative clarity" [Rorty 1980, p. 367368]. Rorty argued that pragmatism must focus on opening up new conversations and keeping them going, even through conflict, a position held by most AR approaches in which discussion, communication, and collaboration among all stakeholders are fundamental elements to the generation of knowledge and the production of change.

AR differs from other research approaches in its ontological, epistemological, and methodological commitments [McNiff and Whitehead 2006]. These underlying assumptions put the researcher and the partnerships with research participants at the center of the process of inquiry, shading all of the ways in which data are collected, analyzed, and reported and change is implemented.

Ontological commitments in research define the way we view ourselves in relation to our work and to other people, including research participants, collaborators, and the community at large. AR requires that people become particularly aware of these commitments, because the researchers must be deeply engaged with the research site. In this way, an AR approach argues that no research can be value neutral, because researchers bring their own values with them into the field. Researchers inherently act in relation to the field site, the research literature, and the available resources. Furthermore, researchers influence and are influenced by others involved in the project 
who bring values of their own. Thus, AR is openly and explicitly value laden and morally committed [McNiff and Whitehead 2006]. Because AR is focused on implementing some change, and that change is meant to "improve" the situation being studied, AR researchers must understand the values they and their community partners bring to the project so as to interrogate explicitly what they hope to achieve, why they hope to achieve it, and what makes them believe the solutions they are attempting will do so.

Epistemologically, AR researchers are committed to the idea that knowledge evolves. The goal of an AR project is to understand a specific situation and develop localized solutions. In this model, generalizability is not necessary or even desirable. Instead, other models of scientific merit are emphasized, including the notion of cross-contextual transfer of solutions and dependability of the research results. AR takes a fundamentally postmodern approach [Stringer 2007, p. 97]. Whereas modern thought rests on the idea that the world is knowable and science is about learning the rules of the fixed and knowable world, a postmodern perspective argues that knowledge is produced inherently by social processes and thus is not based on a set of objective truths. Furthermore, AR's emphasis on democratic and collaborative inquiry leads to an orientation towards knowledge as co-constructed. All people affected by, or having an effect on, an issue should be involved not only in the processes of divining solutions to the issue but also in the processes of research inquiry [Stringer 2007]. Both practitioners (be they HCI professionals or "domain experts" from healthcare, education, and so on) and researchers have valuable knowledge to contribute, and AR rests on the assertion that all participant contributions are taken seriously and treated with equal weight [Greenwood and Levin 2007].

AR methodology is open-ended and iterative. The primary focus of AR is to implement action iteratively, in which action can include a policy or process change, the introduction of new technology, or other intervention, and significant measures of the work are both the quality of research results produced and the feasibility of the solution(s) that emerged. AR utilizes cycles of inquiry that include planning, action, and reflection, in which the action being undertaken is continually designed and evaluated with research results emerging throughout these cycles. AR can incorporate multiple methods and welcomes the use of both qualitative and quantitative methods. The only methods not applicable to an AR approach are those that distance the researchers from problems and questions of inquiry to ensure "objectivity" or avoid "contamination."

In this article, I describe AR as a platform for HCI researchers to conduct socially meaningful and scientifically rigorous research. I first describe the historical path AR has taken over the last century. I then outline the means by which scientific rigor is ensured and measured in AR and the processes by which HCI researchers might conduct $\mathrm{AR}$ in practice with examples from my own work to illustrate these steps. Finally, I close with a discussion of the relationship of AR to current approaches in HCI and how AR may be usefully applied to HCI research moving forward.

\section{HISTORY AND ORIGINS OF ACTION RESEARCH}

In the Introduction, I provided some guidance about the pragmatist, postmodern, and democratic ideals of AR. It is well worth understanding, however, the intellectual climates and events that led to the myriad forms of AR known today. Peters and Robinson [1984] provide a thorough review of the history as well as an analysis of the shared understandings of contemporary action researchers. Here, I overview some of the history of AR with an eye towards HCI, specifically tracing the origin of sociotechnical thought in participatory research theories and methods.

Kurt Lewin, a European psychologist who left Europe at the beginning of the Second World War to escape Nazi persecution, is typically credited with the term "action 
research" and its early definitions. His first foray into the production of research with the goal of developing knowledge in a holistic fashion in situ while working towards a particular goal was focused on the encouragement of American women to cook tripe, rather than more scarce beef [Lewin 1943]. He trained a set of women to cook using tripe (action) and then studied their results in their homes, engaging with the women as well as with their families (holistic and natural) to construct knowledge (research) related to minimizing the need for beef destined for troops (goal). Although this research project was closer to a natural experiment, with all the trappings of authoritarian scientific research efforts, it had a clear goal in mind and so changed thinking about experimentation at the time. Lewin viewed change as a clear process with a beginning, intermediate states, and successful completion. Contemporary views of AR recognize the debt they owe to Lewin but go beyond this formulation to characterize change as part of ongoing dialogue [Gustavsen 1992] and efforts to create knowledge with and through sustainable change [Elden and Levin 1991]. Lewin's legacy in social science research and in $\mathrm{AR}$ was to create space for researchers to perform new roles. Rather than being distant observers, they could now be engage in problem solving alongside their "research subjects." Furthermore, judgments of quality would now include the requirement that a workable solution to some real life problem be developed.

AR suffered some decline in favor in the 1960s because of its close relationship to political activism [Stringer, p. 9]. However, AR was revived in Europe, with members of the Tavistock Institute in London and the Norwegian Industrial Democracy Project bringing Lewin's ideas from America to major post-war redevelopment industrial democracy projects [Gustavsen 1992; Greenwood and Levin, p. 19-20); Trist and Bamforth 1951; Emery and Thorsrud 1976]. These efforts resulted in a major change in thinking within organizational research towards the idea of sociotechnical systems, in which organizations and technologies are considered in concert, a revolutionary idea at the time [Emery and Thorsrud 1976]. In concert with this sociotechnical thinking, Emery and Thorsrud further argued that the "psychological job demands" must be considered simultaneously in the design and implementation of both organizational and technological change. These changes were meant to achieve the end goal of "semiautonomous groups" who can solve problems independent of management when given the right resources [Emery and Thorsrud 1976]. The sociotechnical view that emerged from the Norwegian project rejects both Tayloristic command and control thinking and human relations thinking. Whereas the sociotechnical approach places social and organizational concerns separate from technologies and insists that no social nor technological change should be undertaken without the other [Greenwood and Levin 2007, p. 22], a position now very familiar to HCI researchers. In particular, Bansler notes how "Rolf Hoyer raised the issue of socio-technical systems design at the NordDATA Conference in 1970" [Hoyer 1971, as cited in Bansler 1989]. The legacy of these issues and considerations in the current practices of HCI and User-Centered Design stems from the solutions available to the systems designers and researchers at the time: they could "re-educate systems designers" or engage a "participative approach to systems development ... because [end users] unlike systems experts-possess detailed knowledge of the organization and the work practices in question" [Bansler 1989].

European ideals about industrial democracy, along with the impact they made to formulations of AR, returned to the US shortly after the conceptualization of sociotechnical thinking. Louis Davis began teaching a sociotechnical design course at UCLA in the 1970's [Davis and Taylor 1972] as a means for "high performance industrial production" [Greenwood and Levin 2007, p. 24]. The economic and political contexts of the US at this time altered the focus of the sociotechnical view to one of ensuring productivity from workers and sometimes "union busting" rather than increasing democracy 

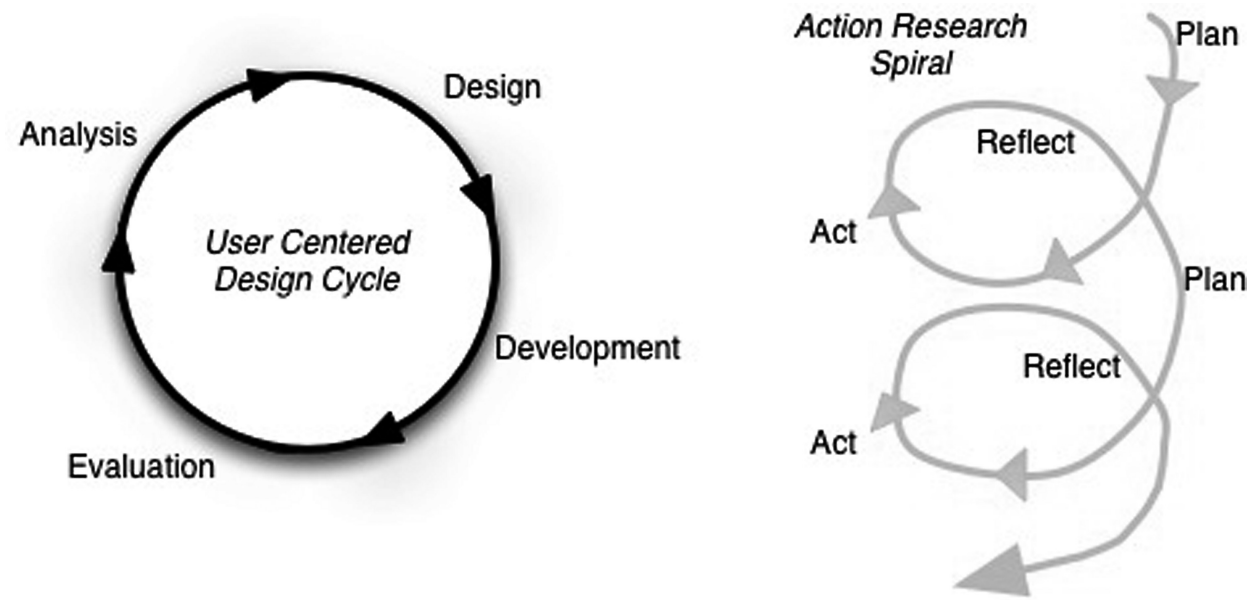

Fig. 1. User-Centered Design is commonly depicted as a cyclical process of design, development, evaluation, and analysis. AR is more commonly represented as a spiral, as in this figure, but is also sometimes represented as a cycle of planning, action, and reflection.

in the workplace with the goal of increased democracy everywhere as in Scandinavia [Greenwood and Levin 2007, p. 24-25].

The intertwined ideas of AR and sociotechnical thinking in organizations by no means stopped in the "Western" world of Europe and the US. Japan used these kinds of problem-solving techniques to handle issues in their production lines [Ishikawa 1976], and the ideas have become popular with researchers and service groups eager to help the "global south." The Southern Participatory Action Research and Participatory Community Development movements have much to teach the Human-Computer Interaction for Development (HCI4D) and Information and Communications Technologies for Development (ICT4D) communities. "To commit to AR in these circumstances is to affirm solidarity with the oppressed and to declare an adversarial role toward the powers that be." [Greenwood and Levin 2007, p. 30] Examples of these early efforts include Paulo Friere's efforts to use adult education to liberate the oppressed [Friere 1970] and "Participatory Rural Appraisal" in which research facilitators lead conversations among community members to plan and support change efforts [Chambers 1997].

Over time, the historically related and conceptually intertwined ideals and ideas of AR, industrial democracy, and sociotechnical thinking as outlined above have spread across the world. This proliferation has encouraged the development of new design methods, such as Scandinavian (or Cooperative) Design [Ehn and Kyng 1987, 1991] and Participatory Design [Asaro 2000; Kensing 2003; Muller 2007; Schuler and Namioka 1993], as well as new approaches to social science inquiry (e.g., [Bray 2000; Tang and Joiner, 2006]). Most contemporary HCI projects are not explicitly pursued as AR. However, the thinking, motivation, and methods used in user-centered design and research can be traced to the overall sociotechnical thinking that emerged from Lewin's $\mathrm{AR}$ and Dewey and others' pragmatism. Additionally, the cyclic approaches common to HCI, including those from user-centered design (see Figure 1) are similar to AR in privileging iteration and building on past experiences.

\section{SCIENTIFIC RIGOR AND AR}

AR is cyclical in nature, with an emphasis on problem formulation, design of an intervention, action (e.g., deploying the intervention), observation of the effects of the action, 
reflection, and then redefinition of the problem to start the cycle again. Visualizations of this process alternately show $\mathrm{AR}$ as a cycle in circular format or a spiral with the circles progressing in some manner. The goal then is not to arrive at the solution to a given problem but to attempt to create a solution that is some way "better" than previous solutions and helps the actors to learn through the action they take.

The idea of scientific inquiry as cyclical and progressive is not new, and certainly even in the "hard sciences" researchers must attempt to make hypotheses, gather data, reflect on the results and reformulate new hypotheses based on what they have learned. The difference in AR, however, is threefold. First, AR calls for action-by both the researchers and their community partners-as an explicit part of the process of inquiry. Action is a means for developing knowledge. As Lewin famously noted, "The best way to understand something is to try to change it." Second, AR requires scientists to observe their own roles in the process, recognizing and embracing their own influence in the research not as "contamination" or "bias" but as an inevitable part of the social construction of scientific knowledge. Finally, AR emphasizes understanding of the local context and development of local solutions without an eye for or the privileging of generalizable results.

How then can one demonstrate scientific rigor without the potential for generalizability? AR has several answers to this question all of which center on the notion that trustworthiness is a valid and appropriate alternative to generalizability in scientific inquiry [Lincoln and Guba 1985]. Trustworthiness stems from four distinct but related concepts: credibility, transferability, dependability, and confirmability [Stringer 2007]. Mackay and Fayard [1997] suggest a related solution to concerns about bridging science and design, the idea of triangulation, or use of multiple research methods at once. AR is particularly interested in the development of scientific knowledge and supporting the needs of community partners with the design artifacts as means for accomplishing both those tasks rather than the design artifacts being the ends themselves. Thus, triangulation may be useful for supporting the trustworthiness of an AR project while meeting the needs of the researchers and their partners. The notion of trustworthiness as a measure of scientific rigor can be-and often is-applied to other related approaches to research (e.g., ethnographic methods, collaborative inquiry), but I here focus on these issues as they apply to the standard of rigor for AR in particular.

AR is particularly well suited to address issues of credibility and the integrity of studies. First, the prolonged engagement common to AR projects ensures that the kinds of deep-seated emotional responses or hidden tacit knowledge that are nearly impossible to retrieve in a single interview or focus group will emerge. Second, AR projects typically include persistent and explicit observation over this extended period of engagement enabling researchers to gather data directly in the field as well as from informant accounts. Furthermore, both in interviews and observations, AR places an emphasis on participant language and perspectives as opposed to the layering of scientific language from the literature on participant concepts. To this end, Stringer advocates use of the verbatim principle, in which researchers use terms and concepts "drawn from the words of the participants themselves" to "minimize the propensity to conceptualize events through their own interpretive lenses" [Stringer 2007, p. 99]. Third, AR ensures credibility of data through the inclusion of multiple perspectives which can allow conflict, disagreement, and therefore data triangulation to occur [Lincoln and Guba 1985] followed by member checking - in which informants verify data collected about them-and debriefing-in which participants are encouraged to voice concerns and comment on the science itself. Furthermore, through an emphasis on standpoint analysis, by which researchers are encouraged to understand and to describe both their own perspectives from their cultural backgrounds and those of the participants with whom they are working [Stringer 2007; Smith 1989, Denzin 1997], 
AR reminds us that no singular account with one voice can describe the myriad complex viewpoints in any research setting. Finally, the credibility and validity of AR knowledge is measured to a large degree by the "workability" of solutions-that is, their ability to address real problems in the lives of the participants [Greenwood and Levin 2007, p. 63]. The workability requirement of solutions enforces the tight link between theory and practice by ensuring that theoretical knowledge generated in the field is returned to the field in the form of some sort of action that can be evaluated.

AR intentionally de-emphasizes the notion that research results can or should be made generalizable to some larger population beyond the one present. Researchers engaged directly and closely with communities, as in AR, recognize the inherent contextualization and localization of any developed solution. Thus, the goal is instead transferability. To accomplish this goal, data must be collected, analyzed, and described as transparently as possible (dependability). Furthermore, enough evidence must be presented to confirm the events transpired as described (confirmability).

This transparency in the development of solutions, collection of data about them, and analysis in results enables other researchers-or community members and other stakeholders in related situations - to trust the results enough to examine what is similar and what is different about their setting in an attempt to replicate parts of the solution while changing others. Thus, AR does not say that no solution can ever be successful outside of the local context for which it was developed. Instead, AR provides a rigorous framework for generating and sharing sufficient knowledge about a solution that it may potentially be transferred to other contexts.

\section{DOING AR IN HCI}

AR shares many methods and issues familiar to HCI researchers: working with community partners, engaging in fieldwork, and designing and developing solutions iteratively. However, an AR approach alters these processes in significant ways. First, the researcher in an AR project takes on the role of a "friendly outsider" [Greenwood and Levin 2007, p. 124-128]. The researcher as friendly outsider is an approach that explicitly rejects the idea that researchers should distance themselves from the subjects of their research in the name of objectivity and requires instead that they become "coaches" skilled at opening up lines of communication and facilitating research activities with community partners rather than designing and implementing research about them. Likewise, the research facilitator co-designs interventions and change with community partners not for them. Finally, this view privileges local knowledge as being as important as scientific or scholarly knowledge, and thus all involved are co-investigators of, co-participants in, and co-subjects of both the change and evaluation activities of the project. In this section, I describe some of the considerations and procedures relevant to taking an AR approach in HCI with examples from my own work when appropriate.

\subsection{Research Questions and Problem Statements}

The first step in many scientific research projects is to formulate a problem statement or collection of research questions. In AR, these research questions should be developed collaboratively in partnership with members of the community you wish to engage and thus tend to be inherently interdisciplinary in nature. Thus, the first step in an AR project is often to engage with a community partner. Furthermore, AR inherently includes the development of some action-in the case of HCI research, often a technological intervention. Before such an intervention can be designed, vision and operational statements should be crafted collaboratively [Stringer 2007, p. 151]. Vision statements allow the entire team to work together to decide what the issues are and how all of the concerns of the people involved will be accounted throughout the process. 
Vision statements often arise from substantial fieldwork, surveys, focus groups and interviews, activities that map well to the HCI concept of "formative" research preceding the initial stages of prototyping.

As one example, in working with an afterschool program that supported teaching children about technology in inner city Atlanta, I struggled to craft a vision with the local leaders of the program for successful change in their efforts. The dominant issue in our struggles was whether the program, which appeared successful in the literature and thus was being replicated in Atlanta, would in fact translate from the program in which it originated in a larger city in the Northeast United States. I was inclined to follow the literature and thus viewed the appropriate changes to be in line with getting their program "back on track" with the national efforts. The local leaders, however, believed the processes and ideas that originated elsewhere would not work for their population. Thus, I then spent several months conducting fieldwork to understand the nuances of their population and the implementation of the program at their site before we could begin to craft a collaborative vision statement. By working together over these months, we were ultimately able to articulate multiple research questions and a general direction that incorporated portions of each of our original ideas and some that emerged during our time working together. These research questions ultimately were both substantially more relevant to the real issues at hand and more credible in terms of developing knowledge.

Operational statements follow from vision statements and specifically detail how all of the individuals involved will work together to ensure that the vision statements can be met [Stringer, p. 151]. Operational statements can be hard to craft and even harder to support and commit to completing. Thus, the action researcher, as research facilitator, must work to support participants in communicating with one another, compromising, and working to prioritize some activities over others-and in systems design and development, some functionality over others. Again, it is important to recognize here that the researchers have some expert knowledge (e.g., what can be done technologically, what timeline and funding resources constrain the project, and so on) as well as the ability to see things as outsiders. However, local knowledge is also incredibly important and should be treated as expert knowledge in its own right. Thus, these decisions should be made collaboratively as part of a negotiation between all of the actors in the project. Addressing these issues early in the project can enhance the commitment of all members of the team to ensuring that both the intervention and the research are completed successfully as well as enable the airing of any potential concerns before they grow into substantial problems.

\subsection{Action and Intervention}

The action in AR can include any of a variety of social and technological changes. AR in HCI should hold at its core, then, the principle that technological and organizational design are "inseparable elements of the same web of relationships" [Greenwood and Levin 2007]. Furthermore, design of these sociotechnical interventions must be conducted collaboratively with community partners. This kind of engagement is related to but distinct from that traditionally advocated in Participatory Design (PD) (e.g., [Greenbaum and Kyng 1992; Muller 2007; Schuler and Namioka 1993]). Both PD and AR stem from the notion that change should be designed and implemented democratically and inclusively [Foth and Axup 2006]. However, the scope of PD is typically more limited to the design of solutions, whereas the scope of AR includes the notion of learning through action. Bodker and Iversen [2002], for example, note that reflection is not always a part of the design process and that professionalization of $\mathrm{PD}$ requires its expansion to include the use of "why" and "where-to" artifacts that support "off-loop reflection" in the PD process. Although this kind of reflection is important to the design, 
and in particular the PD, process, it is not the same as the construction of scholarly knowledge through action required of AR. This kind of learning stems from the extensive co-construction of knowledge before, during, and after the implementation of any change-technological or otherwise. This broad scope ensures that the problems as well as the solutions are collaboratively developed and articulated. Furthermore, the emphasis on research over design in AR drives home the idea that the end goal of $\mathrm{AR}$ is not the best solution to a problem but rather greater understanding of the setting through engagement in change and production of potentially better solutions iteratively and over long periods of engagement. Recognition that the ultimate goal of $\mathrm{AR}$ is to learn through doing can free the designers and researchers in the project from what Stolterman refers to as "design paralysis" that can occur through "endless opportunities" in a messy design space [Stolterman 2008]. AR teams create interventions after thoughtful consideration. However, an attitude that focuses on the outcome of learning something, regardless of the "success" of the design or intervention, can free up the team to attempt interventions that may be risky or underdetermined.

\subsection{Evaluation}

Proponents of AR frequently note that evaluation is never a natural nor a neutral act. Evaluation as a process begs the questions: Who evaluates? What gets evaluated? What power structures and decision processes led to this evaluation strategy? Thus, evaluation in AR, just like problem definition and intervention design, is a value-laden enterprise. AR projects seek to ask and answer research questions as well as those that are of interest to the engaged community partners. Furthermore, AR seeks to "define outcomes in ends that are acceptable to stakeholders, rather than those whose degree of success may be measured against some set of fixed criteria" [Stringer 2007, p. 141]. In this model, evaluation is carried out as a joint construction amongst all the participants. Stakeholder groups are encouraged to place all of their concerns on the table for consideration, review all of the collected data about the project, resolve all of the concerns they can, and prioritize a list of unresolved items (future work, in HCI parlance) [Guba and Lincoln 1989].

These methods inevitably lead to disagreement in some projects. Furthermore, the academic pressures of publishing - and the position of the research facilitators as people who know what is of interest to the academic community-can privilege some portions of the evaluation activities over others. Academic researchers are skilled in arguing their points, have deeper knowledge of the research literature than community partners, and carry with them innate status. Thus, they must be careful of "model monopoly" [Braten 1973], in which the professional researcher dominates the conversation. It is important during evaluation as much as at any point in an AR project to remember that the researcher should act as facilitator for a team not leader of a project and ensure that all of the perspectives are represented in the evaluation and analysis.

A compromise on the means for evaluation to ensure that all perspectives are represented is core to the AR approach, even when it means substantial additional work on the part of the research team. One example of such compromise occurred in my work with a special education school over a two-year period. The research questions we initially developed as a team focused on whether teachers would be able to collect the data required for a particular school practice more efficiently and with less burden using the technological intervention we had designed. As it became clear that the teachers would easily be able to conduct these practices using the technology, the teachers and other school-based professionals began to iterate on the goals of the project, noting that the quality-beyond efficiency - of teacher practice might be changed using the tools we had provided. There were also questions about the quality of teacher-based 
assessments when compared with professional experimental assessments regardless of whether the teachers were using our tool. This quality was best measured by gathering substantially more data and analyzing these data in a way that would produce rigorous results that could be included in year end reports about each child as well as each teacher's progress but would be of little to no interest to the HCI research community. Because our first duty in AR is always to our community partners, we included these issues in our evaluation and analysis. The additional data not only addressed the questions raised by our community partners, it also enabled the co-construction of new knowledge that was unexpected by both the community partners and the research facilitators but emerged through the partnership. These results, though not directly relevant to HCI researchers, were of much interest to the community partners, to special education researchers, and to our interdisciplinary team. Ultimately, their inclusion strengthened the work and led to further publications outside the HCI domain.

\subsection{Writing}

The full inclusion of community partners in AR projects does not end with the implementation of the research nor with the analysis of results. Rather, AR explicitly requires writing with engaged partners. The written material generated from these collaborative activities can come in three forms: reports written for the local group only, scholarly works written for the research community most closely aligned with the community partners, and scholarly works for the research facilitator's research community.

Reports generated for the local group should have a written component, both to serve as a formal record of the project and to ensure the specificity of language and reflection by all participants. However, they may also be accompanied by presentations or even dramatic plays and other performances. For example, in a project in Southern California, we recently created a video report to show to busy members of a local school board who were unable to spend more than a few minutes discussing any particular project or issue at their meetings. These reports can serve multiple purposes in an AR project. First, and most importantly, the activity of creating a report itself makes space for an explicit time during which the entire research team comes together and reflects on the action they have taken. By doing so in writing or another presentation medium, team members must carefully articulate their responses and the results of this reflection to one another and potentially to the outside world. Second, these reports often serve to update local sponsors and gatekeepers (e.g., a local school board or hospital administration) on the project's progress, the research outcomes, and the results of the action in terms these stakeholders use and find important. Third, community partners are often accountable to outside organizations, such as funding organizations. Reports written in lay terms for a local audience can often be appropriated by the community partners in their communication activities with these external bodies. For example, when conducting a research project focused on a technology-oriented curriculum for adolescent girls during summer camp, we worked with a local branch of a major national girls organization. Our community partners used our local report, which included a video, to present the results of the camp to both the national board of their organization and to local donors. We have since used the created video in fund-raising and recruiting efforts at our university, an unexpected benefit of the creation of this video report.

Scholarly works may be more familiar to researchers than the kinds of local reports described above. However, scholarly works-particularly in computer science, information science, and HCI-are almost certainly more familiar to the research facilitators than to the community partners in an AR project. Many community partners may 
never have published in an academic venue, and if they have, it may not have been in these disciplines. Thus, researchers must attend carefully to ensuring empowerment to influence the scholarly production for all members of the team. Specifically, teams should work to ensure that alternate ways of contributing to the scholarly publication are available for those not as comfortable with this format of reporting. Additionally, scholarly publications should be submitted to places that can help the careers of both the research facilitators and the community partners when possible. Top tier conference publications are often the primary goal for HCI researchers (e.g., CHI, CSCW, etc.). However, the computer science tradition of low acceptance rates and high prestige being afforded to these venues does not well translate into many other disciplines. Thus, publication venues and discussions about journals as opposed to conferences should be made collaboratively among the team. At times, the decision may be made to publish in one venue rather than another, but whatever the decision, it should be made collaboratively when possible. Furthermore, an appropriate amount of time must be built into the writing plan to ensure for translation of language among different communities and inclusion of everyone's input. When writing a paper for a computing venue, for example, the HCI research facilitators may need to take extra time to explain the venue, the types of papers, and the questions of interest in this community to the research partners. Often it would be simpler and more expedient to skip these steps, writing the reports within the academic portion of the research team and then asking for feedback on a nearly completed draft from the research partners. However, to meet the goals of a truly collaborative AR experience, the entire team should be included from the beginning when possible, and a variety of reporting mechanisms should be employed.

\subsection{Moments of Celebration}

Getting results of an AR project published is certainly cause for celebration, and presenting the results whether at a local event or a national conference provides the team with a defined moment of celebration. However, in AR projects, because there is no clearly defined ending point in most cases, it is also important to recognize intermediate moments of celebration throughout the project.

In one research project in a school, teachers were asked to perform a set of activities with two children in each of their classes. They worked with me as well as with my community research partner in the schools to complete the tasks in their classrooms over the course of approximately three to five weeks per child. Once everything for an individual child was completed, we brought the teacher a gift bag filled with things she needed for her classroom: hand sanitizer, snacks, school supplies, and so on. Each time they would receive their gifts, the teachers called over their aides and sometimes the students as well as to publicly open the gift bags and join us in thanking the entire classroom and celebrating the completion of one portion of the research effort. These kinds of public displays of celebration can be much more effective in building good will and compensating research participants for involvement than simple cash payments.

In this same project, we also celebrated at bigger milestones. Once all four teachers involved had completed their work with two children each, the first phase of our project was completed. We took advantage of the ending of the school year for these teachers, which coincided with their completion of this first phase, to throw a party at my house. At this party, all of the researchers on the academic side who had helped in building the system we were testing, transcribing interviews, and other activities were present along with the teachers, school administrators, aides, and other team members from the schools. Many of the people present were meeting each other for the first time, with only a few of us having been heavily involved across sites. The team should be 
emphasized during these moments of celebration not the individuals. So, at this party, I gave everyone a present from both the academic research team and the community research team and thanked them collectively and very briefly.

$\mathrm{AR}$ requires sustained long-term engagement with research sites and community partners. This kind of relationship and effort can be exhausting to all involved. Particularly, as milestones are met and the iterative cycle of the project continues, it can be easy to lose some of the drive and focus that began the project in the first place. Thus, using moments of celebration to demark beginnings of new phases and endings of old ones can serve to build more collaborative teams as well as to reinvigorate everyone involved.

\subsection{Leaving the Site}

Although AR projects tend not to begin with defined ending points in mind, invariably the realities of the academic process and the constraints of the community partners' lives necessitate that the research facilitators leave the site at some point. This time can be a painful one for all involved. In the worst cases, the team wishes to keep working together but a change at the field site has eliminated the project, the academic team has lost funding, or some other problem has befallen the project. However, more frequently, members of the team have begun to recognize that the time for the collaborative part of the project may be ending. Faculty members move, and students complete their degrees. Furthermore, successful AR projects result in sustainable, dependable change, which can be less interesting from a research standpoint than the implementation of novel solutions and the study of changes immediately following. Thus, action researchers must be prepared to leave the sites and the people with whom they have become intimately intertwined, and their research collaborators must also be prepared for this inevitability.

In AR, the goal is ultimately to create sustainable change. That is to say, once the research facilitators leave, the community partners should be able to maintain the positive changes that have been made. In many AR projects, the changes made are based in creation of new or changing of old policies, the development of new programs, restructuring of staff roles, and so on. In HCI, however, AR project changes include the deployment of novel technologies. Thus, one of the challenges to leaving the AR site is ensuring that the technologies can be left behind and if left behind can be maintained. It is neither in the best interests of the academic researchers-who have limited resources and other commitments-nor the community partners-who should be made to feel in power and in control of their own projects, particularly after the facilitators leave-for the technological infrastructure to continue to be maintained by the academic partners.

In some AR projects with which I have been engaged, such as those at hospitals and medical centers, IT support is already available within the organization. These individuals can be trained to maintain the equipment brought into the research site by the AR project. Of course, the request for this additional work on the part of the IT organization should be managed carefully as all relationships and new activities should be in AR project. As an example, in one project I developed, a simple mobile phone application to help medical clinicians implement a change in the way they monitored compliance with a home-based intervention. The IT support person who worked with this medical team primarily focused on more traditional enterprise issues (e.g., ensuring the video conferencing system was working before meetings, troubleshooting email, and setting up servers). As part of the project, however, I had meetings with him to discuss his ideas for the phone application. He requested some changes be made to the back-end of the system so that he could more easily manage it, which I was able to make. After a few weeks of use, he no longer needed my help and had begun managing all parts of 
the system along with a nurse he had pulled into the process simply because she likes technology and wanted to learn more. Although my involvement in the project lasted for many months after this transition, when I did eventually leave the team, they had already become self-sustaining.

In other organizations, however, this solution may not be viable. For example, in many schools, although IT support personnel are available, they are usually already spread incredibly thin and cannot easily take on additional responsibilities. In such a situation, a member of the original community partner research team or a research participant at the field site might take on the role of champion for the project and volunteer to maintain the technologies moving forward. This situation can offer a solution to the issue of sustainable change but should be managed carefully, because the change in role for this individual can effect a change in status or power dynamics within the team. Such was this case in a school-based effort in which two teachers wanted to continue to use the system we had developed after we left the research site. One had been enthusiastic from the beginning and, though she had no formal training, had a particular aptitude for handling computing systems. The other had originally been wary of the system and only engaged with it positively towards the end of my involvement in the site. Ultimately, we chose to leave the equipment in the hands of the teacher who had always demonstrated enthusiasm and aptitude. This decision strained their relationship, which was already tenuous for other reasons, and my relationship with the teacher who had not been chosen. Had we had the resources available, it would have been a better choice ultimately to provide them both with equipment and instruction for long-term maintenance.

\subsection{Ethics}

I first learned about AR in May of 2005 at the Public Responsibility in Medicine and Research (PRIM\&R) conference. PRIM\&R as an organization is dedicated to education and research on the topic of research ethics, and their events are one of the primary places Internal Review Board (IRB) administrators and board members go for information about how to conduct and to oversee ethical research. I was there as a newly minted member of my institution's IRB to get the basics in training and education, but I was also there as a curious researcher tangling with my own ethical considerations in my work. I stumbled into the AR session, because the talks there were focused on the ethical struggles of engaged projects like needle exchange programs and transformation of school curricula for inner city students.

A heated discussion around the purview of the federal guidelines for research ethics emerged from this session. The point of concern was the federal definition of research in the United States:

\footnotetext{
Research means a systematic investigation, including research development, testing and evaluation, designed to develop or contribute to generalizable knowledge. [Department of Health and Human Services 2009]
}

The fundamental issue at hand was not, as one might expect, whether AR is in fact research despite having an emphasis on local knowledge over generalizable. Everyone in the room agreed that $\mathrm{AR}$ is research. Instead, the discussion focused on whether the federal definition of research ought to be changed to include AR more explicitly. Since that discussion years ago, the federal definition has not changed, but the vast majority of IRBs at US institutions and other ethical governing boards outside of the US do treat $\mathrm{AR}$ as human subjects research, requiring the same kind of ethical oversight as these other approaches. The challenge here for action researchers is immense. IRB protocols typically demand extensive pre-planning with clear research questions at the outset. AR demands the flexibility to adapt the research agenda and methods 
as the project unfolds. In the last five years, as I more explicitly engaged in AR, I have worked closely with IRBs at multiple institutions to get approval for this kind of work, but it requires extra effort and careful thought for all involved. In particular, documenting a process by which decisions are made and asking key partners to become trained and certified in human subjects research ethics (typically by computer-based training program provided by the university) can both relax the consent documentation requirements and ensure that a truly informed collaborative research process is in place.

Of course, research ethics is a much bigger issue than simply who provides oversight for the ethical conduction of the research. The standard requirements of any research project apply in AR: people can refuse to participate or leave the study any time, their data will be shown to them and returned at their behest, data will be protected and securely stored with no disclosure of identifiable information without consent. However, the participatory nature of AR also requires special ethical considerations. Not only must participants understand the research, they must be allowed to be in positions of greater power than those afforded the "subjects" of a controlled study or even the participants in a design project, in which the "designer has to make all kinds of decisions and judgments, such as, how to frame the situation, who to listen to, what to pay attention to, what to dismiss, and how to explore, extract, recognize, and choose useful information from all these potential sources" [Stolterman 2008]. As participants in the research and co-creators of the research design, their input must be taken seriously and afforded the same consideration as those of more traditional research collaborators. Furthermore, in AR projects, the researchers and community partners will often become very close.

The relationships that emerge from these partnerships must be observed carefully such that coercion can be minimized. I experienced this issue most apparently in a research project I was conducting in the public schools during my doctoral work. Although one classroom aide was uncomfortable with parts of the research, he was careful not to be critical of the project to me and expressed not wanting to "get in the way" of my completing my work, which he recognized as fundamental to my ability to graduate. Eventually, through extensive discussion with me, he was willing to more clearly articulate his discomfort and work with me to find a solution to moving him out of the situation he disliked. These kinds of circumstances and relationships must be monitored carefully throughout the research process.

An additional ethical challenge is one of sustainability of the change. AR project teams have the shared end goals of creating sustained change and learning through those changes. Ensuring continuation of the change is an enormous challenge, however, to any AR team but perhaps particularly to those involving technological interventions, as described in "Leaving the Site." Thus, describing the level of commitment and available resources the researchers have at the beginning of the project can be an essential element in ensuring full transparency and shared knowledge and power amongst the research team and community partners.

Finally, a significant ethical challenge of conducting AR is choosing what kind of action to undertake. Action researchers, as researchers, may have their own professional goals including getting promoted or a new job, meeting the requirements of a granting agency, and so on. At the same time, these researchers by definition are attempting to facilitate meeting the goals of the community partners. Invariably, these teams are likely to find themselves in situations in which multiple changes are possible to address multiple problems. Because AR is not necessarily concerned with finding the solution to any issue but rather with iteratively and collaboratively developing multiple solutions, compromises can typically be met. To navigate these complex ethical issues successfully, however, both research facilitators and community partners must be open and 
honest in communication with one another to craft plans moving forward that balance the needs and goals of everyone involved.

\section{DISCUSSION}

HCI is a highly multi-disciplinary and multi-method field of inquiry. In the last twenty years, the HCI community has also experienced a dramatic upsurge in work that seeks to heal societal ills, that engages deeply with community partners, and that necessitates getting out from behind one's desk and into the field.

The HCI community strongly supports iterative user centered design and collaborative and democratic processes like participatory design. Additionally, systems development and design communities have regularly engaged in cyclical product development processes that privilege intense engagement with the future users of their products. For example, in Highsmith's history of the Agile Manifesto, he notes that Agile methodologists are "about delivering good products to customers by operating in an environment that does more than talk about 'people as our most important asset' but actually "acts" as if people were the most important, and lose (sic) the word 'asset"' [Highsmith 2001]. User-centered design (UCD) also uses a cyclical approach of gathering formative information about user needs and experiences, designing and testing prototype systems, and creating new designs and understanding based on these past experiences.

However, it is important to note that although software design and development bears many similarities to AR, particularly participatory and iterative approaches to these activities, it is not the same as AR. Most notably, the end product of AR is learning and scholarly knowledge, whereas the end product of software design and development is typically a technological artifact. In a paper focused on the ways in which HCI draws together methods and approaches from a variety of intellectual backgrounds-science, engineering, social science, art, and so on-Rogers [2004] notes that there is a "gap between the demands of doing design and the way theory is conceptualized". This observation underscores the prime difference between $\mathrm{AR}$ and design approaches like PD and UCD. These methods and approaches, however, due to their shared history and values, can augment one another [Foth and Axup 2006]. Both are valuable to HCI research and practice but should be considered and understood as the individual approaches they are.

AR is focused on local solutions to local problems. Research projects in HCI also often result in local solutions to local problems. However, the tendency in the writing is to follow conventional social, information, and computer sciences practices of focusing on the ability for what was learned through these local engagements to generalize. Furthermore, studies of technology use that look more like traditional social science (e.g., statistically significant surveys, fieldwork conducted on research subjects not with research participants, etc.) still dominate the HCI journals and conferences. This model does not always fit well with research engagements for which solving the problems at the site of inquiry with the people who are directly experiencing these problems is privileged over specific scientific processes and goals.

In other related fields, such as communications, people have begun to call for understanding and use of $\mathrm{AR}$ as a solution to these challenges. At the same time, action researchers in these domains have developed new models of AR in response to the particular issues of those fields. For example, Hearn et al. [2009] describes New Media Action Research and Foth [2006] argues for Network Action Research as models of AR appropriate for the design and study of mobile communications technologies and other ICT.

In this article, I am not attempting to develop nor advocate for a particular strand of AR. Nor do I think it is appropriate for all research in HCI to attempt to use $\mathrm{AR}$ methods and approaches. Rather, this article is meant to bring awareness to the 
idea of AR for people who are doing research that involves substantial community engagement and collaboration. For those who are doing this kind of work already, this article should serve to provide some of the vocabulary and methods needed to ensure scientific rigor and true collaboration with community partners. At the same time, this article is meant to discourage HCI researchers from working on projects for social good just for the sake of "doing good." "Too often people engage in meaningful participatory and democratizing change processes" and then claim to be doing AR, but there is no "research" element to the project [Greenwood and Levin 2007, p. 99]. This kind of behavior can raise concerns as evidenced by scholarly critiques [Sorenson 1992] and reviews from program committees, journal editors, and funding agencies. We must, therefore, as a research community begin to borrow from AR both the language to describe engaged research processes and the commitment to transparency in data collection and analysis that leads action researchers to produce and consume credible scientific knowledge from these projects.

AR has long engaged the tensions between what research partners and collaborators want to accomplish and what is "research worthy" and publishable. These issues are central to the move from "workability" to credible knowledge. Local workability is the central aim of any AR project with the underlying commitment that whatever is important to the community partners should be important to the designers and academic researchers as well. However, workability in AR is only one key data point, not the end point of the research. Comparison with the literature and deep engagement with why choices were made and how they can be compared or transferred to other similar projects with the same or different outcomes allows for the advancement of credible knowledge beyond the feasibility of the intervention to enact sustainable change locally. This kind of effort is not about generalizability but about transcontextual credibility, an issue that our journal, conference, and grant review processes should begin to take into account.

AR offers HCI researchers theoretical lenses, methodological approaches, and pragmatic guidance for constructing credible knowledge alongside collaborative projects that democratically engage community partners to address significant social challenges. By borrowing from AR, HCI researchers can augment the substantial strides that have already been made in using interactive computational technologies to enact social change and ensure that goals towards appropriate scientific rigor, trustworthiness, and transferability of results are met. AR provides a platform by which researchers can make impact measured not by publication and citation counts alone but also through substantial sustainable change.

\section{ACKNOWLEDGMENTS}

Thank you to Ellie Harmon, Melissa Mazmanian, Six Silberman, Monica Tentori, Bill Tomlinson, and Khai Truong for their thoughtful comments on earlier drafts of this work. Thank you to the ToCHI reviewers and Associate Editor Mary Beth Rosson for their comments and critique on an earlier version of this work.

Finally, I owe a substantial debt to the many community partners with whom I have conducted research over the last several years.

\section{REFERENCES}

Asaro, P. M. 2000. Transforming society by transforming technology: the science and politics of participatory design. Account. Manage. Inf. Tech. 10, 257-290.

Bach, P. M. and Twidale, M. 2010. Involving reflective users in design. In Proceedings of CHI'10. ACM, 2037-2040.

BalaAm, M., Fitzpatrick, G., Good, J., and Luckin, R. 2010. Exploring affective technologies for the classroom with the subtle stone. In Proceedings of CHI'10. ACM, 1623-1632. 
BAnsler, J. 1989. Systems development research in Scandinavia: Three theoretical schools. Scand. J. Inf. Syst. 1, 1, 3-20.

BASKERVILLE, R. AND LEE, A. S. 1999. Distinctions among different types of generalizing in information systems research. In Proceedings of the IFIP TC8 WG8.2 International Working Conference on New Information Technologies in Organizational Processes: Field Studies and Theoretical Reflections on the Future of Work. 49-66.

Baskerville, R. ANd PRIEs-HeJe, J. 1999. Grounded action research: A method for understanding IT in practice. Account. Manag. Inf. Tech. 9, 1-23.

Benford, S., Bederson, B. B., Åkesson, K., Bayon, V., Druin, A., Hansson, P., Hourcade, J. P., Ingram, R., Neale, H., O’Malley, C., Simsarian, K. T., Stanton, D., Sundblad, Y., and Taxén, G. 2000. Designing storytelling technologies to encouraging collaboration between young children. In Proceedings of CHI'00. ACM, $556-563$.

Blomberg, J. L. and Henderson, A. 1990. Reflections on participatory design: lessons from the trillium experience. In Proceedings of CHI'90. ACM, 353-360.

Bodker, S. ANd Iversen, O. S. 2002. Staging a professional participatory design practice: Moving PD beyond the initial fascination of user involvement. In Proceedings of the 2nd Nordic Conference on HumanComputer Interaction. ACM, 11-18, DOI: 10.1145/572020.572023.

Braten, S. 1973. Model monopoly and communication: Systems theoretical notes on democratization. Acto Sociologica 16, 2, 98-107.

BRAY, D. B. 2000. A bird in the cup: Grinding towards environmental and social justice in the world of coffee. Orion Afield. Winter. (reprinted in program for 3rd Sustainable Coffee Conference.

Chambers, R. 1997. Whose Reality Counts? Putting the First Last. Intermediate Technology Publications.

Damn, C. H., Hansen, K. M., and Thomsen, M. 2000. Tool support for cooperative object-oriented design: gesture based modeling on an electronic whiteboard. In Proceedings of CHI'O0. ACM, $518-525$.

Davis, L. E. and Taylor, J. C. 1972. Design of Jobs. Penguin.

Denzin, N. K. 1997. Interpretive Ethnography. Sage Publications.

Department of Health and Human Services. 2009. Protection of human subjects. Code of Federal Regulations. 46.102.

DewEy, J. 1976. Essays on logical theory. 1902-1903. Southern Illinois University Press.

Dewey, J. 1991/1927. The Public and Its Problems. Ohio University Press.

Ehn, P. And Kyng, M. 1987. The collective resource approach to systems design. In Computers and Democracy - A Scandinavian Challenge, Avebury, 17-58.

Ehn, P. AND Kyng, M. 1991. Cardboard computers: Mocking-it-up or hands-on the future. In Design at Work. Laurence Erlbaum Associates, 169-196.

Elden, M. And Levin, M. 1991. Action Research for Educational Change. Open University Press.

Emery, F. ANd Thorsrud, W. 1976. Democracy at Work. Martinus Nijhoff.

Fотн, M. 2006. Network action research. Action Res. 4, 2, 205-226.

Foth, M. AND AxuP, J. 2006. Participatory design and action research: Identical twins or synergetic pair? In Proceedings of the Participatory Design Conference. 93-96.

Friere, P. 1970. The Pedagogy of the Oppressed. Herder \& Herder.

Gitau, S., Marsden, G., AND Donner, J. 2010. After access: challenges facing mobile-only internet users in the developing world. In Proceedings of CHI'10. ACM, 2603-2606.

Greenbaum, J. And Kyng, M. (Eds.). 1992. Design at Work: Cooperative Design of Computer Systems. L. Erlbaum Assoc. Inc.

Greenwood, D. J. And Levin, M. 2007. Introduction to Action Research 2nd Ed. Sage Publications.

GuBA, E. G. AND Lincoln, Y. S. 1989. Judging the quality of fourth generation evaluation. In Fourth Generation Evaluation. Sage, 228-51.

Gustavesen, B. 1992. Dialogue and Development. Van Gorcum.

Hearn, G., Tacchi, J., Foth, M., And Lennie, J. 2009. Action Research and New Media: Concepts, Methods and Cases. Hampton Press.

Highsmith, J. 2001. History: The agile manifesto. http://agilemanifesto.org/history.html September 2010.

Hirano, S., Yeganyan, M. T., Marcu, G., Nguyen, D. H., Boyd, L., and Hayes, G. R. 2010. vSked: evaluation of a system to support classroom activities for children with autism. In Proceedings of CHI'10. ACM, 1633-164. 
Hochheiser, H. ANd LAZAR, J. 2007. HCI and societal issues: A framework for engagement. Int. J. Hum. Comput. Interact. 23, 3, 339-374.

IshIKAWA, K. 1976. Guide to Quality Control. Asian Productivity Organization.

JAMES, W. 1948. Essays in Pragmatism. Hafner.

JANCKe, G., Grudin, J., AND Gupta, A. 2000. Presenting to local and remote audiences: Design and use of the TELEP system. In Proceedings of CHI'00. ACM, 384-391.

Johnson, J. 1990. Participatory design of computer systems. In Proceedings of CHI'90. ACM, 141-144.

Kensing, F. 2003. Methods and Practices in Participatory Design. ITU Press.

KIM, S. AND PAUlos, E. 2010. InAir: Sharing indoor air quality measurements and visualizations. In Proceedings of CHI'10. ACM, 1861-1870.

Kuznetsov, S. And Paulos, E. 2010. UpStream: Motivating water conservation with low-cost water flow sensing and persuasive displays. In Proceedings of CHI'10. ACM, 1851-1860.

Lee, A. S. ANd Baskerville, R. L. 2003. Generalizing generalizability in information systems research. Inf. Syst. Res. 14, 3, 221-243.

Lewin, K. 1935. A Dynamic Theory of Personality. McGraw-Hill.

Lewin, K. 1943. Forces behind food habits and methods of change. Bull. Nat. Res. Council 108, 35-65.

LEwIN, K. 1946. Action research and minority problems. J. Soc. Iss. 2, 4, 34-46.

LewIN, K. 1948. Resolving Social Conflicts. Harper.

Lincoln, Y. S. AND GubA, E. G. 1985. Naturalistic Inquiry. Sage Publications.

MACKAY, W. E. AND FAYARD, A. L. 1997. HCI, natural science and design: A framework for triangulation across disciplines. In Proceedings of Designing Interactive Systems (DIS'97). ACM 223-233.

Margolis, J. ANd Fisher, A. 2003. Unlocking the Clubhouse: Women in Computing. The MIT Press.

MÄkelä, A., Giller, V., Tscheligi, M., ANd Sefelin, R. 2000. Joking, storytelling, artsharing, expressing affection: A field trial of how children and their social network communicate with digital images in leisure time. In Proceedings of CHI'00. ACM, 548-555.

McNiff, J. and Whitehead, J. 2006. All You Need to Know About Action Research. Sage Publications.

MCTAGGART, R. 1996. Issues for participatory action researchers. In New Directions in Action Research. Falmer Press.

Muller, M. J. 2007. Participatory design: The third space in HCI (revised). In Handbook of HCI 2nd Ed. Erlbaum.

Palen, L. 2010. Better Odds than "Snowballs in Hell?" -or- What Might Action Research Do for HCI?. In Proceedings of the Human-Computer Interaction Consortium. USA.

Peters, M. and Robinson, V. 1984. The origins and status of action research. J. Appl. Behavior. Sci. 20, 2, 113-124.

Ramachandran, D., CANNY, J., DAS, P. D., AND Cutrell, E. 2010. Mobile-izing health workers in rural India. In Proceedings of CHI'10. ACM, 1889-1898.

RAPAPORT, R. 1970 Three dilemmas in action research. Strong. Famil. Learn. Exch. Bull. 23, 6, 499-513.

Rogers, Y. 2004. New theoretical approaches for human-computer interaction. In Ann. Rev. Inf. Sci. Tech. 38, 87-143.

RoRTy, R. 1980 . Philosophy and the Mirror of Nature. Princeton University Press.

Schuler, D. ANd NAmioka, A. 1993. Participatory design: Principles and practices. Erlbaum.

Sмгтн, D. E. 1989. Sociological theory: Methods of writing patriarchy. In Feminism and Sociological Theory. Sage Publications, 34-64.

Smyth, T. N., Etherton, J., ANd Best, M. L. 2010. MOSES: Exploring new ground in media and post-conflict reconciliation. In Proceedings of CHI'10. ACM, 1059-1068.

Sorenson, A. B. 1992. Action research in work life. Norweg. J. Soc. Res. 33, 213-230.

Stolterman, E. 2008. The nature of design practice and implications for interaction design research. Int. J. Des. 2, 1, 55-65.

Stringer, E. T. 2007. Action Research. Sage Publications.

TAng, Y. And JoIner, C. 2006. Synergic Inquiry: A Collaborative Action Methodology. Sage Publications.

Tarkan, S., Sazawal, V., Druin, A., Golub, E., Bonsignore, E. M., Walsh, G., and Atrash, Z. 2010. Toque: Designing a cooking-based programming language for and with children. In Proceedings of CHI'10. ACM, New York, NY, 2417-2426.

Trist, E. ANd BAmforth, K. W. 1951. Some social and psychological consequences of the lonwall method of coal getting. Human Relat. 4, 3-38. 
Walsh, G., Druin, A., Guha, M., Foss, E., Golub, E., Hatley, L., Bonsignore, E., and Franckel, S. 2010. Layered elaboration: a new technique for co-design with children. In Proceedings of CHI'10. ACM, $1237-1240$.

Wilcox, L., Morris, D., Tan, D., and Gatewood, J. 2010. Designing patient-centric information displays for hospitals. In Proceedings of CHI'10. ACM, 2123-2132.

Yoo, D., Zimmerman, J., Steinfeld, A., AND Tomasic, A. 2010. Understanding the space for co-design in riders' interactions with a transit service. In Proceedings of CHI'10. ACM, 1797-1806.

Received June 2010; revised November 2010; accepted February 2011 